\title{
BMJ Open Relationships between social spending and childhood obesity in OECD countries: an ecological study
}

\author{
Atsushi Miyawaki (D) , 1,2 Charlotte Elizabeth Louise Evans (i) , \\ Patricia Jane Lucas, ${ }^{4}$ Yasuki Kobayashi ${ }^{1}$
}

To cite: Miyawaki A, Evans CEL, Lucas PJ, et al. Relationships between social spending and childhood obesity in OECD countries: an ecological study. BMJ Open 2021;11:e044205. doi:10.1136/ bmjopen-2020-044205

- Prepublication history and additional material is published online only. To view please visit the journal online (http://dx.doi. org/10.1136/bmjopen-2020044205).

Received 26 August 2020 Revised 04 February 2021 Accepted 08 February 2021

\section{Check for updates}

\section{Author(s) (or their} employer(s)) 2021. Re-use permitted under CC BY-NC. No commercial re-use. See rights and permissions. Published by BMJ.

${ }^{1}$ Department of Public Health, Graduate School of Medicine, The University of Tokyo, Bunkyoku, Tokyo, Japan

${ }^{2}$ Health Services Research and Development Center, University of Tsukuba, Tsukuba, Ibaraki, Japan

${ }^{3}$ School of Food Science and Nutrition, University of Leeds, Leeds, UK

${ }^{4}$ School for Policy Studies, University of Bristol, Bristol, UK

Correspondence to

Dr Atsushi Miyawaki;

amiyawaki-tky@umin.ac.jp

\section{ABSTRACT}

Objectives The burden of childhood obesity is clustered among children in low-socioeconomic groups. Social spending on children-public welfare expenditure on families and education-may curb childhood obesity by reducing socioeconomic disadvantages. The objective of this study was to examine the relationship between social spending on children and childhood obesity across the Organisation for Economic Cooperation and Development (OECD) countries.

Design Ecological study.

Setting Data on social spending on children were obtained from the OECD Social Expenditure Database and the OECD educational finance indicators dataset during 2000-2015. Data on childhood obesity were obtained from the NCD Risk Factor Collaboration database.

Participants Aggregated statistics on obesity among children aged 5-19 years, estimated for OECD 35 countries based on the measured height and weight on 31.5 million children.

Outcome measures Country-level prevalence of obesity among children aged $5-19$ years.

Results In cross-sectional analyses in 2015 , social spending on children was inversely associated with the prevalence of childhood obesity after adjusting for potential confounders (the gross domestic product per capita, unemployment rate, poverty rate, percentage of children aged $<20$ years and prevalence of childhood obesity in 2000). In addition, when we focused on changes from 2000 to 2015, an average annual increase of US\$100 in social spending per child was associated with a decrease in childhood obesity by 0.6 percentage points for girls $(p=0.007)$ and 0.7 percentage points for boys $(p=0.04)$ between 2000 and 2015, after adjusting for the potential confounders. The dimensions of social spending that contributed to these associations between the changes in social spending on children and childhood obesity were early childhood education and care (ECEC) and school education for girls and ECEC for boys. Conclusion Countries that increase social spending on children tend to experience smaller increases in childhood obesity.

\section{INTRODUCTION}

The prevalence of childhood obesity has almost doubled in high-income countries during the last two decades. Current estimates

\section{Strengths and limitations of this study}

This is the first study that has investigated the relationship between public social spending on children and childhood obesity in the Organisation for Economic Cooperation and Development (OECD) countries.

- We further focused on which dimensions of public social spending contributed most to these relationships.

- We did not focus on content and generosity of individual social policies nor private social spending. Future work should focus more on the impact of individual social policies on childhood obesity.

- Although our sample included high-income and higher middle-income countries, findings were based on OECD countries' data and might not be generalisable to countries outside of this group.

suggest nearly 1 in 10 children are obese. ${ }^{1}$ Obesity in early life is an urgent public health issue due to its subsequent health consequences, including adult obesity, ${ }^{2}$ early onset of non-communicable diseases, ${ }^{3}$ premature death $^{34}$ and its influence on children's psychosocial development. ${ }^{5}$ Childhood obesity is considered to have substantial economic burdens at the societal and individual level. ${ }^{67}$ Policy makers are increasingly responding to this growing public health crisis.

Although the proximal causes of this epidemic of obesity primarily are in individual behaviours such as higher consumption of food high in fat and sugar and increased sedentary behaviour, ${ }^{8}$ these factors are shaped by upstream determinants related to socioeconomic conditions and the obesogenic environment. ${ }^{9}$ Several studies have demonstrated that low-socioeconomic status of households is a risk factor for childhood obesity. ${ }^{10}{ }^{11}$ For example, those with both less education and lower family income are more likely to consume highly obesogenic fast foods. ${ }^{12}$ Recognising such social determinants of obesity, the WHO has recently recommended 
improving access to high-quality food in disadvantaged families in tandem with policies including taxation on unhealthy food and nutritional labels. ${ }^{13}$ Besides these public health interventions, another possible approach is to reduce socioeconomic disadvantage itself, through social protection (eg, income supplements for families and public investments in education). ${ }^{14}$ Although there is a growing literature on the importance of social protection on adult obesity, ${ }^{15-17}$ less attention has been paid to the roles of such social protection policies in childhood obesity prevention. This gap partly relates to the difficulty of estimating social spending at the individual level.

Although all high-income countries have social protection programmes, there are large cross-national variations in their generosity. ${ }^{18} 19$ Social spending-how much the government spends on social protection ${ }^{20}$-has been considered as an indicator to quantitatively gauge the generosity of social protection programmes in a country or region. Several studies have recently recognised the importance of social spending as an indicator of macrosocial determinants of health and demonstrated the association between social spending and better population health outcomes including life expectancy, infant mortality and low birth weight. ${ }^{18}{ }^{21}$ If the same macrosocial determinants are drivers of childhood obesity, increasing social spending on children will similarly operate as an upstream approach to curb childhood obesity. The possible mechanisms may include tax credits and paid parental leave, that increase or stabilise household income, or food vouchers offered to low-income families, which enable them to improve the quality of family meals. ${ }^{22}$ Higher quality nutritional and physical education at school also encourages children to have a healthier diet and to be more active. ${ }^{23}$ However, little is known so far about the relationship between gross public social spending on children and childhood obesity.

To bridge this knowledge gap, in this study, we sought to answer the following questions using data from the Organisation for Economic Cooperation and Development (OECD) countries. First, is social spending on children associated with the prevalence of childhood obesity? Second, if so, which types of social spending contribute to this association? In this study, we focus on betweencountry differences, considering gross social spending as a macrosocial indicator. The mechanisms via which social spending may influence childhood obesity are numerous and, at the individual level, childhood obesity is likely better predicted by individual circumstance. To estimate the impact of macroeconomic policies, we report on differences at this level.

\section{METHODS}

\section{Study design and sample}

We conducted a panel data analysis of 35 OECD countries using the NCD Risk Factor Collaboration (NCD-RisC) database ${ }^{24}$ which provides trends of childhood obesity during 1975-2016 in 200 countries. We examined social spending on children using (1) the OECD Social Expenditure Database (SOCX) ${ }^{25}$ and (2) the OECD educational finance indicators dataset. ${ }^{26}$ The SOCX database includes internationally comparable statistics on public social spending ('public' means 'by the central, state, or local government ${ }^{20}$ ) across 35 OECD countries. The spending is categorised into 'old age,' 'survivors,' 'incapacity related,' 'family,' 'active labour market program,' 'unemployment,' 'housing' and 'other social policy areas.' We focused on the category 'family' because this category is most likely to measure direct benefits to children. ${ }^{27}$ Although we anticipate that children will benefit from indirect spending on, for example, unemployment programmes and housing, including these categories would overestimate the sums reaching families with children. We did not include private social spending ('private' means that it came from other sources than the general government) because it was not available for most countries in the SOCX dataset. Although education is considered as an essential aspect of social spending, ${ }^{19}$ spending on school education is not included in the SOCX datasets (early childhood education and care (ECEC) is included). Thus, we obtained information on public social spending on school education from the OECD's educational finance indicators dataset. Furthermore, we examined several country-level sociodemographic variables, including the population of children aged $<20$ years, the gross domestic product (GDP) per capita, unemployment rate and poverty rate, using the OECD. Stat database. ${ }^{28}$ We examined data during 2000-2015, for which reliable data on both childhood obesity and social spending were available. We excluded Lithuania from all analyses due to missing data in most years.

\section{Measures}

Outcome variable: prevalence of childhood obesity

We used the age-standardised prevalence $(\%)$ of childhood obesity among children aged 5-19 years (standardised to the WHO standard population), which has been estimated by sex using a Bayesian hierarchical model based on the measured height and weight on 31.5 million children. ${ }^{24}$ Childhood obesity was defined as more than 2 $\mathrm{SD}$ above the age and sex-specific WHO growth reference median. ${ }^{29}$

\section{Exposure variable: social spending on children}

Our primary exposure variable was total social spending on children, which was defined as the sum of (1) public social spending on family, which includes benefits on family allowance, maternal and parental leave, ECEC and others (the components are shown in online supplemental table $\mathrm{S} 1)^{25}$; and (2) public social spending on school education (primary to post-secondary non-tertiary). Specifically, public social spending on family includes (1) child-related cash transfers to families with children, including income-tested child allowances, public income support payments during periods of parental leave, and income support for single-parent families; (2) public 
spending on services for families with children, including the direct subsidisation of childcare and ECEC facilities, public childcare support through earmarked payments to parents, and home help services for families; (3) financial support for families via the tax system, including child tax allowances and tax credits. ${ }^{30}$ Public social spending on school education includes direct expenditure on educational institutions (eg, public spending on instruction services, university research, and ancillary services such as meals and transport to schools) as well as educationrelated public subsidies given to households and administered by educational institutions. ${ }^{26}{ }^{31}$ Social spending on children was expressed as the purchasing power parity (PPP)-adjusted US dollars (fixed price, 2010 as the baseline year) per child aged $<20$ years.

Our secondary exposure variables were five dimensions of social spending on children (family allowance, maternal and parental leave, ECEC, school education and other benefits). This disaggregation of social spending on children was conducted following the OECD's datasets to examine which dimensions of social spending contributed to the relationship between the social spending on children and childhood obesity.

\section{Adjustment variables}

We adjusted for countries' demographics and the 'baseline' prevalence of childhood obesity in 2000. Demographics consisted of three economic indicators (GDP per capita, unemployment rate and poverty rate) and the percentage of children aged $<20$ years, because these factors could affect both the social spending on children ${ }^{19}$ and the prevalence of childhood obesity. The 'baseline' prevalence of childhood obesity was also included as countries that had suffered from high obesity prevalence in the past may invest more in social programmes to mitigate against childhood obesity.

\section{Statistical analysis}

Basic social characteristics derived across the included OECD countries in 2015 were GDP per capita (PPPadjusted US dollars), unemployment rate (for the total population), poverty rate (the ratio of the number of people aged 18-65 years whose income falls below half the median household income of the total population, before tax and transfer) and children aged $<20$ years as a percentage of total population.

Next, we cross-sectionally investigated the relationship between total social spending on children and childhood obesity across OECD countries, using the 2015 data. We plotted the prevalence of childhood obesity against social spending on children and estimated the correlation between them using a Pearson's correlation. We also examined the association between them by using a multivariable linear regression model that adjusted for the demographic indicators (GDP per capita, unemployment rate, poverty rate and percentage of children aged $<20$ years) in 2015 , and the prevalence of childhood obesity in 2000 . The analyses were separately conducted for each sex here (and hereafter) because the pattern of childhood obesity varied by sex across countries. ${ }^{1}$ In this analysis, we substituted the latest year data for Denmark, Poland, Netherlands and New Zealand, for which the 2015 data on social spending were unavailable.

Then, to effectively investigate the association between social spending on children and childhood obesity within the same country, we examined the longitudinal trends in total social spending on children and childhood obesity during the period 2000-2015. To account for the difference in economic growth by countries, we first estimated the average annual growth in social spending on children adjusted by the growth in GDP per capita for each country using linear regression (online supplemental method S1). Next, we illustrated the association between the growth in social spending and childhood obesity by plotting the absolute change in the prevalence of childhood obesity from 2000 to 2015 against the average annual change in social spending on children for countries and estimating the correlation between them using a Pearson's correlation. We then investigated the association between them by using a multivariable linear regression model that adjusted for the changes in demographic indicators (unemployment rate, poverty rate and percentage of children aged <20 years) from 2000 to 2015 and the prevalence of childhood obesity in 2000. In this longitudinal analysis, we substituted the latest year data/the earliest year data when the 2015/2000 data were unavailable.

Finally, we used the secondary exposure variables by replacing total social spending on children with five dimensions of social spending on children (family allowance, maternal and parental leave, ECEC, school education and other benefits), and repeated multivariable linear regressions. ${ }^{16}$ In this analysis, we examined 29 OECD countries for which information on all the dimensions of social spending on children were available (Denmark, Mexico, Netherlands, New Zealand, Poland and the USA were excluded). All analyses were conducted using Stata V.15 (StataCorp LLC, College Station, Texas, USA). A $\mathrm{p}<0.05$ was considered as statistically significant.

\section{Post hoc analyses}

To investigate potential heterogeneous effects according to economic development, we divided OECD countries in half according to GDP per capita in 2000 and repeated the regression analyses for each group (ie, countries with lower vs countries with upper GDP per capita).

\section{Patient and public involvement}

The current study involved secondary use of publicly available aggregated data. The study did not involve patients and the public in any way and did not require ethics review.

\section{RESULTS}

\section{Basic characteristics across OECD countries}

PPP-adjusted GDP per capita varied across OECD countries in 2015 , ranging from $\$ 16660$ in Mexico to $\$ 87825$ in Luxembourg (table 1). The unemployment rate was $7.9 \%$, on average, ranging from $3.4 \%$ in Japan to $24.9 \%$ in Greece. 
Table 1 Characteristics of Organisation for Economic Cooperation and Development 35 countries in 2015

\begin{tabular}{|c|c|c|c|c|}
\hline Country & $\begin{array}{l}\text { GDP per capita } \\
\text { (US\$) }\end{array}$ & $\begin{array}{l}\text { Unemployment rate } \\
(\%)\end{array}$ & $\begin{array}{l}\text { Poverty rate } \\
(\%)\end{array}$ & $\begin{array}{l}\text { Children aged }<20 \\
\text { (\% of population) }\end{array}$ \\
\hline Australia & 45584 & 6.1 & 18.6 & 25.1 \\
\hline Austria & 42906 & 5.7 & 20.9 & 19.7 \\
\hline Belgium & 40900 & 8.5 & 24.5 & 22.6 \\
\hline Canada & 42498 & 6.9 & 20.0 & 22.0 \\
\hline Chile & 20789 & 6.2 & 14.5 & 28.0 \\
\hline Czech Republic & 29874 & 5.0 & 17.3 & 19.7 \\
\hline Denmark & 44760 & 6.2 & 18.7 & 23.1 \\
\hline Estonia & 26023 & 6.2 & 20.0 & 20.6 \\
\hline Finland & 38272 & 9.4 & 23.5 & 21.9 \\
\hline France & 36902 & 10.4 & 26.2 & 24.6 \\
\hline Germany & 42503 & 4.6 & 20.0 & 18.4 \\
\hline Greece & 23649 & 24.9 & 28.9 & 19.4 \\
\hline Hungary & 24254 & 6.8 & 24.0 & 19.7 \\
\hline Iceland & 43726 & 4.0 & 11.5 & 27.0 \\
\hline Ireland & 58229 & 9.9 & 29.9 & 27.7 \\
\hline Israel & 31221 & 5.2 & 18.8 & 36.4 \\
\hline Italy & 33164 & 11.9 & 23.9 & 18.4 \\
\hline Japan & 37036 & 3.4 & 18.4 & 17.3 \\
\hline Latvia & 22237 & 9.9 & 19.9 & 19.4 \\
\hline Luxembourg & 87825 & 6.7 & 25.0 & 22.6 \\
\hline Mexico & 16660 & 4.3 & 16.6 & 37.2 \\
\hline Netherlands & 45855 & 6.9 & 20.1 & 22.6 \\
\hline New Zealand & 33981 & 5.4 & 15.2 & 26.8 \\
\hline Norway & 59430 & 4.3 & 18.1 & 24.4 \\
\hline Poland & 24170 & 7.5 & 21.2 & 20.4 \\
\hline Portugal & 26677 & 12.4 & 22.9 & 19.6 \\
\hline Slovakia & 28423 & 11.5 & 16.8 & 20.7 \\
\hline Slovenia & 28203 & 9.0 & 21.4 & 19.4 \\
\hline South Korea & 34193 & 3.6 & 13.5 & 20.1 \\
\hline Spain & 31753 & 22.1 & 28.8 & 19.8 \\
\hline Sweden & 44832 & 7.4 & 14.5 & 22.8 \\
\hline Switzerland & 54453 & 4.8 & 8.8 & 20.3 \\
\hline Turkey & 22709 & 10.2 & 15.3 & 32.7 \\
\hline UK & 38723 & 5.3 & 20.8 & 23.7 \\
\hline USA & 52105 & 5.3 & 19.8 & 25.7 \\
\hline OECD 35 average & 37558 & 7.9 & 20.0 & 23.1 \\
\hline
\end{tabular}

The GDP per capita was measured as purchasing power parity adjusted US dollars (fixed price, 2010 as the baseline year). Poverty rate shows the ratio of the number of people aged 18-65 whose income falls below half the median household income of the total population, before tax and transfer.

GDP, gross domestic product.

The poverty rate was $20.0 \%$, on average, ranging from $8.8 \%$ in Switzerland to $29.9 \%$ in Ireland. Children aged $<20$ years accounted for $23.1 \%$ of the total population, on average, ranging from $17.3 \%$ in Japan to $37.2 \%$ in Mexico.
Cross-sectional analysis of social spending and childhood obesity

The prevalence of childhood obesity varied across OECD countries in 2015 , lowest in Japan (1.7\% for girls and 

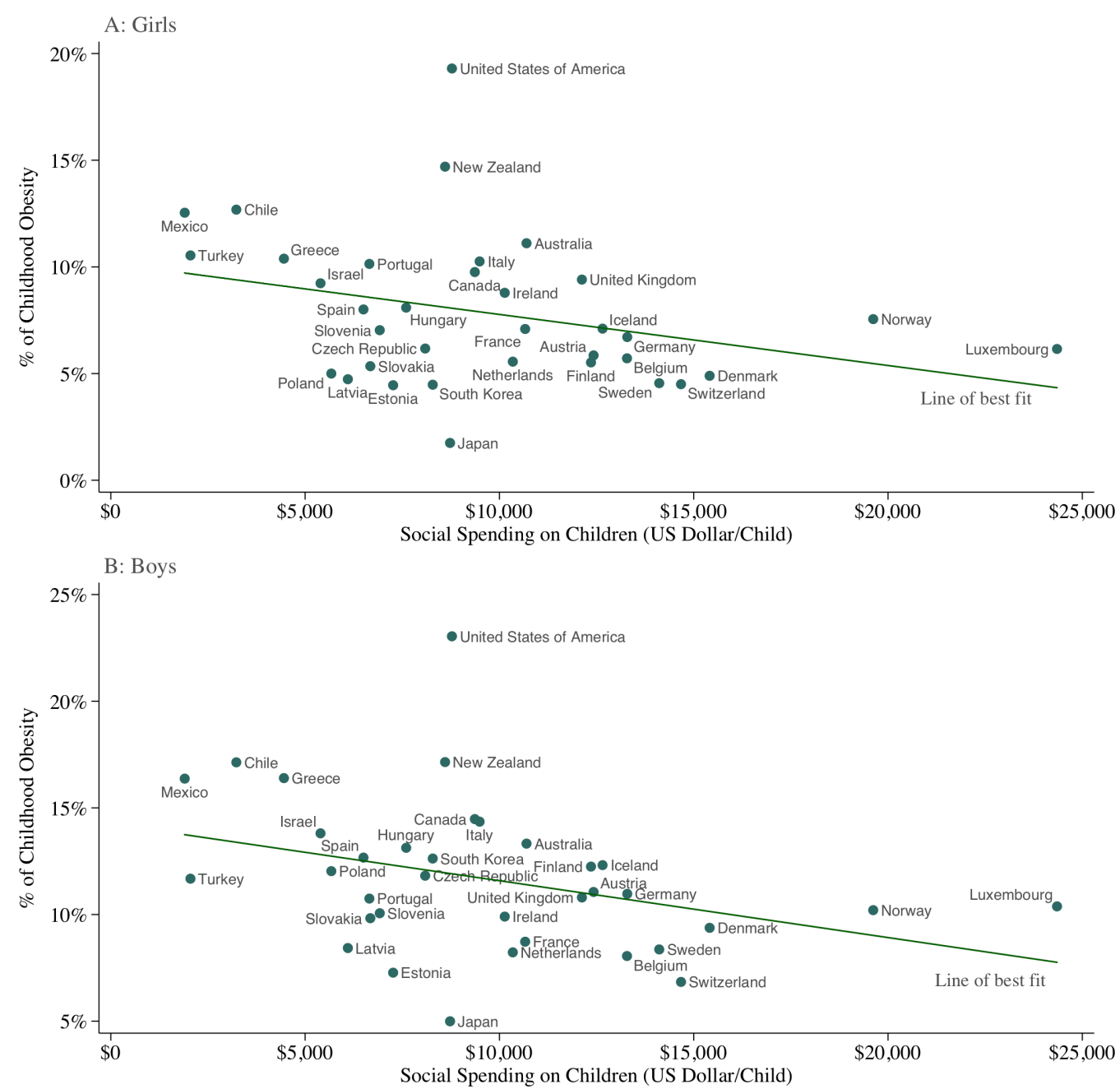

Figure 1 Social spending on children and prevalence of childhood obesity by sex in the Organisation for Economic Cooperation and Development (OECD) countries. Source: Authors' analysis of data from OECD's Social Expenditure Database (SOCX), OECD Education statistics database and NCD Risk Factor Collaboration (NCD-RisC) database. Notes: Data are from 2015 for all countries apart from Denmark (2014), Poland (2014), Netherlands (2011) or New Zealand (2011). The x-axis shows the country-level social spending on children (including cash benefits and tax breaks for families with children, expenditure on childcare or other benefits in kind, and expenditure on primary and secondary education), measured as purchasing power parity (PPP)-adjusted US dollars (fixed price, 2010 as the baseline year) per child aged under 20 years. The $y$-axis indicates the country-level prevalence (\%) of children aged 5-19 years categorised as obesity (body mass index $>2$ SD above the WHO growth reference for children). The lines of best fit show that countries whose governments spend more money on children tend to experience smaller percentages of childhood obesity for both sexes (Pearson's $r=-0.32 ; p=0.06$ for girls and $r=-0.35 ; p=0.04$ for boys).

$5.0 \%$ for boys) and highest in New Zealand (14.7\% and $17.1 \%)$, with the USA as an outlier (19.3\% and $23.0 \%)$ (figure 1). There was considerable variation in PPPadjusted social spending on children. Luxembourg was the highest spender, with social spending on children amounting to $\$ 24350$ per child. The lowest spender was Mexico, which spent $\$ 1901$ per child. When splitting countries into two groups (the upper vs lower half of the population proportion of children) and comparing social spending on children in 2015, there was no substantial difference (mean $\$ 10785$ vs $\$ 8586$; $\mathrm{p}=0.18$ in BrunnerMunzel test). The relationship between social spending on children and the prevalence of childhood obesity was moderate and inverse for girls (Pearson's $r=-0.32 ; \mathrm{p}=0.06$ ) and boys $(\mathrm{r}=-0.35 ; \mathrm{p}=0.04)$. Since the USA appeared to be an outlier for childhood obesity, we conducted a post hoc estimation of correlation coefficients by excluding the US data, but the associations were qualitatively unchanged $(\mathrm{r}=-0.37 ; \mathrm{p}=0.03$ for girls and $\mathrm{r}=-0.40 ; \mathrm{p}=0.02$ for boys $)$. After we adjusted for potential confounders (table 2), we found that countries with higher total social spending on children experienced lower prevalence of childhood obesity $\left(\beta=-0.3 \times 10^{-3} ; \mathrm{p}=0.01\right.$ for girls and $\beta=-0.4 \times 10^{-3}$; $\mathrm{p}=0.02$ for boys).

\section{Longitudinal analysis of social spending and childhood obesity}

During the period 2000-2015, all countries experienced increases in the prevalence of childhood obesity, with the exception of girls in Denmark (figure 2). When we 
Table 2 Association between total or five dimensions of social spending on children (US\$) and the prevalence of childhood obesity (\%): Cross-sectional analyses in 2015

\begin{tabular}{|c|c|c|c|c|c|}
\hline \multirow[b]{2}{*}{ Types of social spending } & \multirow[b]{2}{*}{ Coefficients } & \multicolumn{2}{|l|}{$95 \% \mathrm{Cl}$} & \multirow[b]{2}{*}{$P$ value } & \multirow[b]{2}{*}{ R squared } \\
\hline & & Lower & Upper & & \\
\hline \multicolumn{6}{|l|}{ Girls } \\
\hline By dimensiont & & & & & 0.89 \\
\hline Family allowance & $-0.2 \times 10^{-3}$ & $-0.9 \times 10^{-3}$ & $0.4 \times 10^{-3}$ & 0.43 & \\
\hline ECEC & $-0.5 \times 10^{-3}$ & $-1.5 \times 10^{-3}$ & $0.5 \times 10^{-3}$ & 0.32 & \\
\hline Education & $-0.5 \times 10^{-3}$ & $-1.1 \times 10^{-3}$ & $0.04 \times 10^{-3}$ & 0.07 & \\
\hline Others & $0.1 \times 10^{-3}$ & $-0.7 \times 10^{-3}$ & $0.9 \times 10^{-3}$ & 0.79 & \\
\hline \multicolumn{6}{|l|}{ Boys } \\
\hline Total social spending* & $-0.4 \times 10^{-3}$ & $-0.7 \times 10^{-3}$ & $-0.1 \times 10^{-3}$ & 0.02 & 0.83 \\
\hline ECEC & $-0.7 \times 10^{-3}$ & $-2.1 \times 10^{-3}$ & $0.8 \times 10^{-3}$ & 0.37 & \\
\hline Education & $-0.7 \times 10^{-3}$ & $-1.5 \times 10^{-3}$ & $0.1 \times 10^{-3}$ & 0.07 & \\
\hline Others & $0.1 \times 10^{-3}$ & $-1.0 \times 10^{-3}$ & $1.1 \times 10^{-3}$ & 0.87 & \\
\hline
\end{tabular}

For each sex, we examined the association between social spending on children (PPP-adjusted US dollars) and prevalence of childhood obesity (\%) by using a multivariable linear regression model that adjusted for the countries' demographics (employment rate, poverty rate and percentage of children aged $<20$ years) in 2015 and the prevalence of childhood obesity in 2000 . We reported the coefficient. For example, our results indicated that among girls, a US $\$ 1000$ difference in total social spending per children was associated with a 0.3 percentage points lower prevalence of childhood obesity.

*We regressed the prevalence of childhood obesity on total social spending on children. These analyses were conducted for all the 35 countries.

†We regressed the prevalence of childhood obesity on five dimensions of social spending on children. These analyses were conducted for 33 countries. Mexico and USA were excluded because either dimension of social spending is not available.

ECEC, early childhood education and care.

examined the changes in social spending adjusted by the growth in GDP per capita and changes in the prevalence of childhood obesity, we observed a moderate inverse association between these variables for girls (Pearson's $\mathrm{r}=-0.49 ; \mathrm{p}<0.01)$ and a weak inverse association for boys $(\mathrm{r}=-0.28 ; \mathrm{p}=0.10)$. After we adjusted for potential confounders (table 3), we found that countries with greater increases in total social spending on children also had smaller increases in the prevalence of childhood obesity $\left(\beta=-0.6 \times 10^{-2} ; p=0.007\right.$ for girls and $\beta=-0.7 \times 10^{-2}$; $\mathrm{p}=0.04$ for boys). These estimates indicate that a US $\$ 100$ average annual increase (adjusted by PPP and GDP per capita) per child was associated with a decline in childhood obesity between 2000 and 2015 by $0.6 \%$ for girls and $0.7 \%$ for boys.

\section{Disaggregated social spending and childhood obesity}

Patterns of spending on specific dimensions within the gross social spending figure varied considerably between countries (online supplemental figure S1). On average, $14.5 \%$ of social spending on children was used for family allowance, $6.4 \%$ for maternal and parental leave, $12.4 \%$ for ECEC, $56.2 \%$ for school education and $10.4 \%$ for other benefits in 2015. When we focused on the specific dimensions of social spending in cross-sectional analyses (table 2), we found no evidence that either dimension of social spending on children was associated with the prevalence of childhood obesity. However, when we focused on the changes over time (table 3), we found an inverse association between the change in spending on ECEC and in the prevalence of childhood obesity for girls $\left(\beta=-1.2 \times 10^{-2} ; p=0.045\right)$ and boys $\left(\beta=-2.1 \times 10^{-2} ; p=0.049\right)$. We also found an inverse relationship between the change in spending on school education and the growth in childhood obesity for girls $\left(\beta=-1.1 \times 10^{-2} ; p=0.01\right)$, but not for boys $\left(\beta=-0.5 \times 10^{-2} ; p=0.43\right)$. The change in social spending on family allowance, maternal leave and other benefits were not associated with the growth in the prevalence of childhood obesity for either sex.

\section{Post hoc analyses}

In the stratified analyses according to GDP per capita in 2000, the cross-sectional inverse relationship between total social spending on children and prevalence of childhood obesity was observed among countries with higher GDP per capita ( $p=0.03$ for girls and $p=0.04$ for 

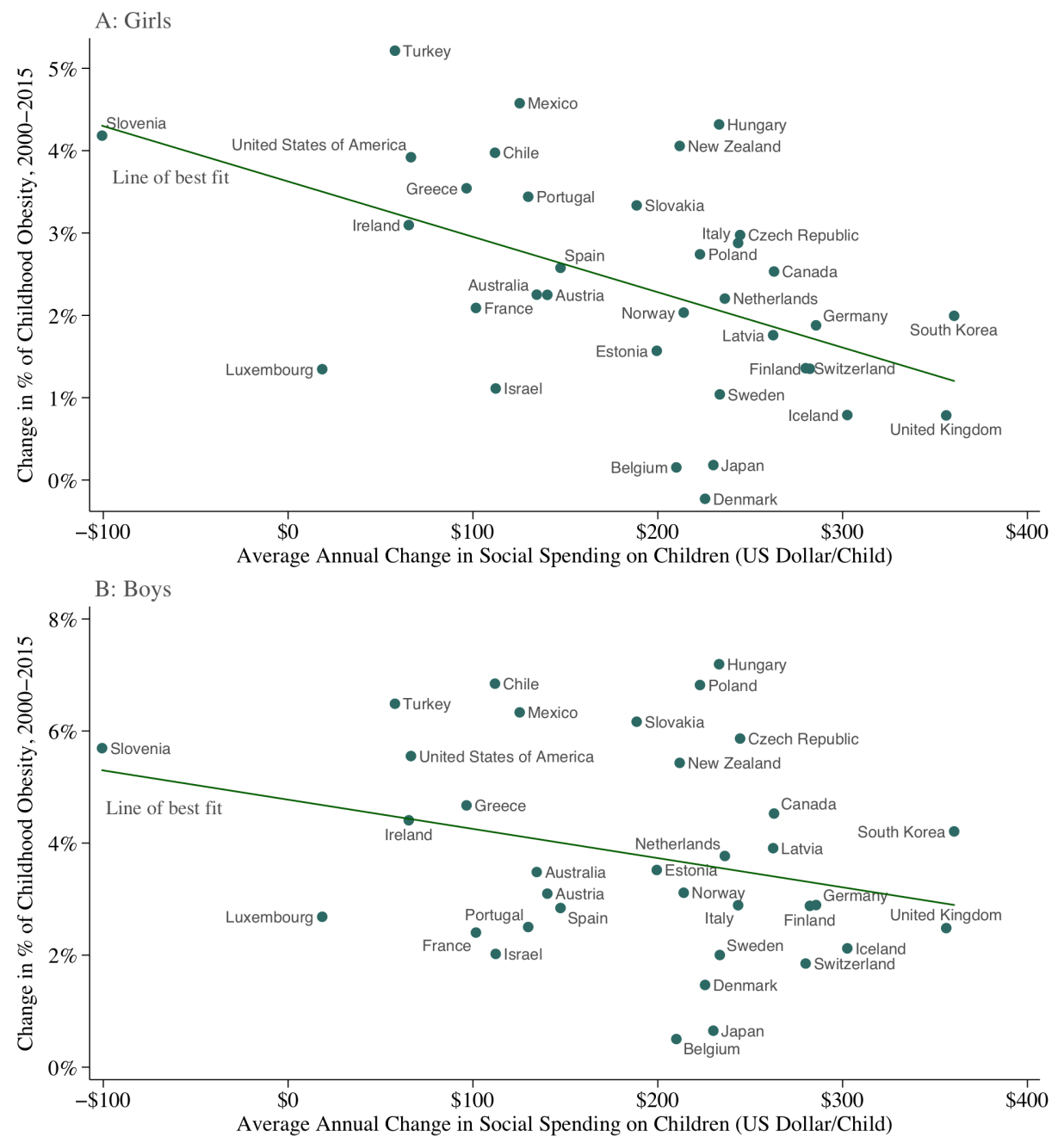

Figure 2 Changes in social spending on children and in the prevalence of childhood obesity from 2000 to 2015 in the Organisation for Economic Cooperation and Development (OECD) countries. Source: Authors' analysis of data from OECD's Social Expenditure Database (SOCX), OECD Education statistics database and NCD Risk Factor Collaboration (NCD-RisC) database. Notes: The $x$-axis shows the average annual change in social spending on children (PPP-adjusted US dollars per child) adjusted by the growth in GDP per capita during 2000-2015. The $y$-axis indicates the absolute change in the prevalence of childhood obesity from 2000 to 2015. The lines of best fit show that changes in social spending on children and the percentage of childhood obesity are inversely associated for both sexes (Pearson's $r=-0.49 ; p<0.01$ for girls and $r=-0.28$; $\mathrm{p}=0.10$ for boys).

boys) (online supplemental table S2). When focusing on disaggregated social spending, we found a cross-sectional inverse association between social spending on maternal and parental leave and prevalence of childhood obesity for boys among countries with lower GDP per capita $(p=0.02)$. In longitudinal analyses, the coefficients for the association between the changes in total social spending and changes in the prevalence of childhood obesity remained negative; however, they did not reach statistical significance regardless of the level of GDP per capita and sex (online supplemental table S3).

\section{DISCUSSION}

Among OECD countries, we found an inverse association between the growth in social spending on children and childhood obesity, after accounting for the underlying difference in social factors that could drive social spending and childhood obesity. What contributed most to this association was social spending on education: ECEC for both sexes, and social spending on school education also contributed notably for girls. These results suggest that OECD countries whose social spending on children increase more tend to experience smaller increases in childhood obesity prevalence in a context where all countries except Denmark showed increasing prevalence in childhood obesity. These findings may highlight the importance of social protection programmes as macrosocial determinants of childhood obesity.

It is not clear why the inverse association between social spending and childhood obesity exist, but the finding that 
Table 3 Association between changes in total or five dimensions of social spending on children (US\$) and the prevalence of childhood obesity (\%): longitudinal analyses from 2000 to 2015

\begin{tabular}{|c|c|c|c|c|c|}
\hline \multirow[b]{2}{*}{ Types of social spending } & \multirow[b]{2}{*}{ Coefficients } & \multicolumn{2}{|l|}{$95 \% \mathrm{Cl}$} & \multirow[b]{2}{*}{$P$ value } & \multirow[b]{2}{*}{ R squared } \\
\hline & & Lower & Upper & & \\
\hline \multicolumn{6}{|l|}{ Girls } \\
\hline Total social spending* & $-0.6 \times 10^{-2}$ & $-1.0 \times 10^{-2}$ & $-0.2 \times 10^{-2}$ & 0.007 & 0.65 \\
\hline By dimension† & & & & & 0.72 \\
\hline Family allowance & $-0.8 \times 10^{-2}$ & $-2.0 \times 10^{-2}$ & $0.5 \times 10^{-2}$ & 0.20 & \\
\hline Maternal and parental leave & $1.0 \times 10^{-2}$ & $-1.5 \times 10^{-2}$ & $3.5 \times 10^{-2}$ & 0.42 & \\
\hline ECEC & $-1.2 \times 10^{-2}$ & $-2.4 \times 10^{-2}$ & $0.03 \times 10^{-2}$ & 0.045 & \\
\hline Education & $-1.1 \times 10^{-2}$ & $-1.9 \times 10^{-2}$ & $0.3 \times 10^{-2}$ & 0.01 & \\
\hline Others & $0.4 \times 10^{-2}$ & $-0.5 \times 10^{-2}$ & $1.3 \times 10^{-2}$ & 0.35 & \\
\hline \multicolumn{6}{|l|}{ Boys } \\
\hline Total social spending* & $-0.7 \times 10^{-2}$ & $-1.3 \times 10^{-2}$ & $-0.03 \times 10^{-2}$ & 0.04 & 0.55 \\
\hline By dimension† & & & & & 0.57 \\
\hline Family allowance & $-1.2 \times 10^{-2}$ & $-3.4 \times 10^{-2}$ & $0.9 \times 10^{-2}$ & 0.26 & \\
\hline Maternal and parental leave & $0.1 \times 10^{-2}$ & $-3.9 \times 10^{-2}$ & $4.1 \times 10^{-2}$ & 0.96 & \\
\hline ECEC & $-2.1 \times 10^{-2}$ & $-4.1 \times 10^{-2}$ & $-0.01 \times 10^{-2}$ & 0.049 & \\
\hline Education & $-0.5 \times 10^{-2}$ & $-2.0 \times 10^{-2}$ & $0.9 \times 10^{-2}$ & 0.43 & \\
\hline Others & $0.2 \times 10^{-2}$ & $-1.3 \times 10^{-2}$ & $1.7 \times 10^{-2}$ & 0.79 & \\
\hline
\end{tabular}

For each sex, we examined the association between the changes in social spending on children (PPP-adjusted US dollars) and the prevalence of childhood obesity (\%) from 2000 to 2015, by using a multivariable linear regression model that adjusted for average annual changes in employment rate and poverty rate, changes in the percentage of children aged $<20$ years and the 'baseline' prevalence of childhood obesity in 2000. We reported the coefficient. For example, our results indicated that among girls, a US\$100 average annual increase in total social spending per child was associated with a 0.6 percentage points decrease in the prevalence of childhood obesity between 2000 and 2015.

*We regressed the change in the prevalence of childhood obesity on the change in total social spending on children. The analyses were conducted for 33 countries. South Korea and Luxembourg were excluded because the average annual change in unemployment rate or poverty rate cannot be calculated (data for more than 2 years are not available).

tWe regressed the change in the prevalence of childhood obesity on the changes in five dimensions of social spending on children. The analyses were conducted for 31 countries. South Korea, Luxembourg, Mexico and USA were excluded because the average annual change in either dimension of social spending or the average annual change in unemployment rate or poverty rate cannot be calculated (data for more than 2 years are not available).

ECEC, early childhood education and care.

the relationship between social spending on children and childhood obesity varies by dimensions of social spending may help to determine the possible mechanisms of this association. Notably, social spending on ECEC was associated with reduced obesity growth rates for both girls and boys. Moreover, school education was associated with reduced growth of obesity among girls. Spending on these education categories may enrich nutritional and physical activity environments that protect against obesity, such as higher quality school meals, ${ }^{32}{ }^{33}$ limited access to energydense competitive foods and beverages at school, ${ }^{34} 35$ and better access to playing fields. ${ }^{36}$ Conversely, schools under financial pressures may adopt unhealthy food policies (sales or advertising of snack foods) in schools or cancel gym classes in order to improve school budgets. ${ }^{37}$ If the high-quality educational environment is protective against childhood obesity, we might predict that public ECEC spending would have a particularly important role since it will increase both quality (eg, through increasing staff-to-child ratios) and uptake (in a context where ECEC is not mandatory in most OECD countries). For example, Norway is the highest ECEC spender, has mandatory subsidised childcare from 1 year and provides the highest quality of ECEC among developed countries ${ }^{35}$; and has low growth in obesity rates within the OECD. This relationship with public ECEC spending is particularly interesting since maternal employment and use of childcare in the earliest years (largely financed privately) have been associated with higher rates of obesity. ${ }^{38-40}$ Our finding supports the view that the reason early childcare is associated with obesity is that it is often lower quality and highly constrained,$^{40}$ suggesting the importance of public spending on high-quality care for reducing childhood obesity. In contrast, in the context of universal provision of school education, the school environment may be more important for girls than boys in influencing levels of physical activity. ${ }^{41}$ However, this mechanism may depend on the social context; another study in the USA showed that the protective effect of increased physical education on obesity was concentrated among boys because 
girls substituted physical education for other activities. ${ }^{42}$ Other possible mechanisms may be through children's health literacy and socioeconomic conditions in the future resulting from public investments in education. ${ }^{43}$ However, without further breakdown of categories of social spending, we can only provide plausible suggestions for what might account for these observed associations.

\section{Comparison with other studies}

Our findings add to a body of work that has explored the relationship between social protection, especially social spending as its indicator, and population health outcomes. Bradley and colleagues demonstrated a link between public social spending and better population health measures in terms of life expectancy, infant mortality rate and low birth weight across OECD countries. ${ }^{18}$ They also found similar associations in the USA between social spending and better health outcomes, including the lower prevalence of adult obesity. ${ }^{21}$ A study by Shim further found that social spending on children, especially spending on the family allowance, was associated with reduced infant mortality in OECD 19 countries. ${ }^{27}$ In Canada, Ng and Muntaner found that indicators of welfare generosity, including social spending on post-secondary education, were associated with reduced mortality. ${ }^{44}$ There is also a growing literature on the effect of social programmes and education on adult obesity. ${ }^{15-17}$ Our study extends these previous studies by further focusing on childhood obesity, one of the top public health issues in the modern context, and therefore reinforces the key roles of social protection policies and social spending as their indicator in population health.

\section{Strengths and limitations of this study}

This is the first study that has investigated the relationship between social spending on children and childhood obesity. We further focused on which dimensions of public social spending contributed most to these relationships. Moreover, we tested the association between social spending and childhood obesity more robustly by examining the association between longitudinal changes as well as cross-sectional relationships. This would have helped to adjust for unobserved country-specific characteristics. For example, the fact that the USA was a clear outlier in the cross-sectional analysis might be due to the country's traditional food and agricultural policies that encourages overconsumption. ${ }^{45}$ These factors would have been effectively controlled for in the longitudinal analysis but not in the cross-sectional analysis.

Our study has limitations. First, as in any ecological study unmeasured confounding will have influenced our findings. For example, countries that spend more of social spending for families may also spend more on public health activities for the prevention of childhood obesity (eg, food labelling and sugar tax) or other social protection programmes that can be protective against childhood obesity at the population level (eg, housing and labour market programmes). ${ }^{46} 47$ Second, we analysed only 35 countries at most, which limits the number of possible adjustment variables that could be included in the regression analyses. Third, our study was unable to identify the exact mechanisms through which social spending was inversely associated with childhood obesity, even though we broke down social spending into several dimensions. We did not have information on individual social policies (eg, childcare quality and availability or free school meals), and it was difficult to isolate the effect of individual social policies. Nevertheless, our findings suggest that public social spending in the broadest sense may be an important macrolevel indicator of child health and well-being, such as childhood obesity. Future work should focus more directly on the impact of individual social policies on childhood obesity. Fourth, the change in social spending on children does not appear to explain all the variation of the growth in the prevalence of childhood obesity. For example, Japan, Belgium and Denmark had a smaller growth in childhood obesity compared with the fitted lines, while several countries, including Hungary, Mexico and Turkey, experienced a larger growth. Therefore, even when this association is causal, the effect of increasing social spending on children on the prevalence of childhood obesity in an individual country may differ by the country's characteristics such as economic inequalities and cultural factors related to food and physical activity. Fifth, our study captures obesity across a wide age range (5-19 years), while many of these policies are age dependent (eg, school impacts are likely to be cumulative after school starting age). Finally, our analysis did not include private social spending. Private social spending may act to partially counter the redistributive impact of public social spending. ${ }^{48}$ Further studies on how changes in the public and private mix in social spending may affect childhood obesity may be required.

Although our sample includes both high-income and higher middle-income countries, findings were based on OECD countries' data and might not be generalisable to countries outside of this group.

\section{CONCLUSIONS}

In summary, we found that OECD countries with larger increases in social spending on children between 2000 and 2015 tended to experience a smaller increase in childhood obesity over the same period. This association appeared to be explained mainly by the change in social spending on early childhood education and care and school education. Our findings may highlight the importance of social spending as a macrosocial indicator in childhood obesity.

Twitter Atsushi Miyawaki @AMiyawaki38 and Patricia Jane Lucas @PatriciaJLucas Contributors AM and CELE conceived the study design. AM analysed data. AM, CELE, PJL and YK interpreted the data. All authors contributed to the draft manuscript and have approved the final version.

Funding AM was supported by the Japan Society for the Promotion of Science (18J13078 and 20K18956) and Social Science Research Council (grant number 
is not applicable). CELE was supported by a mobility award from the University of Leeds (grant number is not applicable).

Competing interests None declared.

Patient consent for publication Not required.

Provenance and peer review Not commissioned; externally peer reviewed.

Data availability statement Data are available in a public, open access repository. The datasets are available from the following websites: NCD-RisC datasets (http:// ncdrisc.org), OECD SOCX datasets (https://www.oecd.org/social/expenditure.htm), and the public spending on education datasets (https://www.oecd-ilibrary.org/ education/public-spending-on-education/indicator/english_f99b45d0-en).

Supplemental material This content has been supplied by the author(s). It has not been vetted by BMJ Publishing Group Limited (BMJ) and may not have been peer-reviewed. Any opinions or recommendations discussed are solely those of the author(s) and are not endorsed by BMJ. BMJ disclaims all liability and responsibility arising from any reliance placed on the content. Where the content includes any translated material, BMJ does not warrant the accuracy and reliability of the translations (including but not limited to local regulations, clinical guidelines, terminology, drug names and drug dosages), and is not responsible for any error and/or omissions arising from translation and adaptation or otherwise.

Open access This is an open access article distributed in accordance with the Creative Commons Attribution Non Commercial (CC BY-NC 4.0) license, which permits others to distribute, remix, adapt, build upon this work non-commercially, and license their derivative works on different terms, provided the original work is properly cited, appropriate credit is given, any changes made indicated, and the use is non-commercial. See: http://creativecommons.org/licenses/by-nc/4.0/.

\section{ORCID iDs}

Atsushi Miyawaki http://orcid.org/0000-0001-6126-1464

Charlotte Elizabeth Louise Evans http://orcid.org/0000-0002-4065-4397

\section{REFERENCES}

$1 \mathrm{Ng} \mathrm{M}$, Fleming T, Robinson M, et al. Global, regional, and national prevalence of overweight and obesity in children and adults during 1980-2013: a systematic analysis for the global burden of disease study 2013. Lancet 2014;384:766-81.

2 Wang LY, Chyen D, Lee S, et al. The association between body mass index in adolescence and obesity in adulthood. J Adolesc Health 2008;42:512-8.

3 Reilly JJ, Kelly J. Long-Term impact of overweight and obesity in childhood and adolescence on morbidity and premature mortality in adulthood: systematic review. Int J Obes 2011;35:891-8.

4 Strand BH, Kuh D, Shah I, et al. Childhood, adolescent and early adult body mass index in relation to adult mortality: results from the British 1946 birth cohort. J Epidemiol Community Health 2012;66:225-32.

5 Daniels SR, Arnett DK, Eckel RH, et al. Overweight in children and adolescents: pathophysiology, consequences, prevention, and treatment. Circulation 2005;111:1999-2012.

6 Cawley J. The economics of childhood obesity. Health Aff 2010;29:364-71.

7 Popkin BM, Kim S, Rusev ER, et al. Measuring the full economic costs of diet, physical activity and obesity-related chronic diseases. Obes Rev 2006;7:271-93.

8 Lobstein T, Jackson-Leach R, Moodie ML, et al. Child and adolescent obesity: part of a bigger picture. Lancet 2015;385:2510-20.

9 Swinburn B, Egger G, Raza F. Dissecting obesogenic environments: the development and application of a framework for identifying and prioritizing environmental interventions for obesity. Prev Med 1999;29:563-70.

10 Bammann K, Gwozdz W, Lanfer A. Socioeconomic factors and childhood overweight in Europe: results from the multi-centre IDEFICS study: socioeconomic factors and childhood overweight. Pediatr Obes 2013;8:1-12.

11 Ueda P, Kondo N, Fujiwara T. The global economic crisis, household income and pre-adolescent overweight and underweight: a nationwide birth cohort study in Japan. Int J Obes 2015;39:1414-20.

12 Townshend T, Lake A. Obesogenic environments: current evidence of the built and food environments. Perspect Public Health 2017;137:38-44.

13 World Health Organization. Report of the Commission on ending childhood obesity: implementation plan. Geneva, 2017. http://apps. who.int/gb/ebwha/pdf_files/WHA70/A70_31-en.pdf
14 Lundberg O, Yngwe MA, Stjärne MK, et al. The role of welfare state principles and generosity in social policy programmes for public health: an international comparative study. Lancet 2008;372:1633-40.

15 Levasseur P. Can social programs break the vicious cycle between poverty and obesity? Evidence from urban Mexico. World Development 2019;113:143-56.

16 Nagano H, Puppim de Oliveira JA, Barros AK, et al. The 'Heart Kuznets Curve'? Understanding the relations between economic development and cardiac conditions. World Dev 2020;132:104953.

17 Etile F. Education policies and health inequalities: evidence from changes in the distribution of body mass index in France, 19812003. Econ Hum Biol 2014;13:46-65.

18 Bradley EH, Elkins BR, Herrin J, et al. Health and social services expenditures: associations with health outcomes. BMJ Qual Saf 2011;20:826-31.

19 Papanicolas I, Woskie LR, Orlander D, et al. The relationship between health spending and social spending in high-income countries: how does the US compare? Health Aff 2019;38:1567-75.

20 OECD. OECD data: social spending 2019.

21 Bradley $\mathrm{EH}$, Canavan M, Rogan E, et al. Variation in health outcomes: the role of spending on social services, public health, and health care, 2000-09. Health Aff 2016;35:760-8.

22 Griffith R, von Hinke S, Smith S. Getting a healthy start: the effectiveness of targeted benefits for improving dietary choices. $J$ Health Econ 2018;58:176-87.

23 Amini M, Djazayery A, Majdzadeh R, et al. Effect of school-based interventions to control childhood obesity: a review of reviews. Int $J$ Prev Med 2015;6:68.

24 NCD Risk Factor Collaboration (NCD-RisC). Worldwide trends in body-mass index, underweight, overweight, and obesity from 1975 to 2016: a pooled analysis of 2416 population-based measurement studies in 128.9 million children, adolescents, and adults. Lancet 2017;390:2627-42

25 OECD. Social expenditure database (SOCX), 2019. Available: https:// www.oecd.org/social/expenditure.htm [Accessed 20 Nov 2019].

26 OECD. Public spending on education (indicator), 2019 [Accessed 20 Nov 2011].

27 Shim J. Social welfare expenditures and infant mortality. Soc Work Public Health 2015;30:567-77.

28 OECD. OECD. Stat 2019 (accessed 20 Nov 2019).

29 de Onis M, Onyango AW, Borghi E, et al. Development of a who growth reference for school-aged children and adolescents. Bull World Health Organ 2007;85:660-7.

30 OECD. PF1.1: public spending on family benefits. Available: http:// www.oecd.org/els/soc/PF1_1_Public_spending_on_family_benefits. pdf [Accessed 25 Aug 2020].

31 OECD. Indicator B1: how much is spent per student? in: education at a glance 2014: OECD indicators, 2014. Available: http://www.oecd. org/education/EAG2014-Indicator\%20B1\%20(eng).pdf [Accessed 25 Aug 2020].

32 Miyawaki A, Lee JS, Kobayashi Y. Impact of the school lunch program on overweight and obesity among junior high school students: a nationwide study in Japan. J Public Health 2019;41:362-70.

33 Jaime PC, Lock K. Do school based food and nutrition policies improve diet and reduce obesity? Prev Med 2009;48:45-53.

34 Council of School Health,. Committee on nutrition. snacks, sweetened beverages, added sugars, and schools. Pediatrics 2015;135:575-83.

35 World Health Organization. School policy framework: implementation of the who global strategy on diet, physical activity and health. Geneva, 2008. http://www.who.int/dietphysicalactivity/SPF-en-2008. pdf

36 World Health Organization. Promoting physical activity in schools: an important element of a health-promoting school, 2007. Available: https://apps.who.int/iris/bitstream/handle/10665/43733/ 9789241595995_eng.pdf?sequence=1\&isAllowed=y [Accessed 10 Dec 2019].

37 Anderson PM, Butcher KF. Reading, writing, and refreshments: Are school finances contributing to children's obesity? J Human Resources 2006;XLI:467-94.

38 Pearce A, Li L, Abbas J, et al. Is childcare associated with the risk of overweight and obesity in the early years? findings from the UK millennium cohort study. Int J Obes 2010;34:1160-8.

39 Hawkins SS, Cole TJ, Law C. Maternal employment and early childhood overweight: findings from the UK millennium cohort study. Int J Obes 2008;32:30-8.

40 Swyden K, Sisson SB, Lora K, et al. Association of childcare arrangement with overweight and obesity in preschool-aged children: a narrative review of literature. Int $J$ Obes 2017;41:1-12. 
41 Jago R, Anderson CB, Baranowski T, et al. Adolescent patterns of physical activity differences by gender, day, and time of day. Am J Prev Med 2005;28:447-52.

42 Cawley J, Frisvold D, Meyerhoefer C. The impact of physical education on obesity among elementary school children. $J$ Health Econ 2013;32:743-55.

43 Ruel MT, Alderman H, Maternal and Child Nutrition Study Group. Nutrition-sensitive interventions and programmes: how can they help to accelerate progress in improving maternal and child nutrition? Lancet 2013;382:536-51.

$44 \mathrm{Ng} \mathrm{E}$, Muntaner $\mathrm{C}$. Welfare generosity and population health among Canadian provinces: a time-series cross-sectional analysis, 19892009. J Epidemiol Community Health 2015;69:970-7.
45 Nestle M. Food politics: how the food industry influences nutrition and health. University of California Press: Berkeley:, 2007.

46 Kirkpatrick SI, Tarasuk V. Housing circumstances are associated with household food access among low-income urban families. J Urban Health 2011;88:284-96.

47 Oddo VM, Nicholas LH, Bleich SN, et al. The impact of changing economic conditions on overweight risk among children in California from 2008 to 2012. J Epidemiol Community Health 2016;70:874-80.

48 Goudswaard K, Caminada K. The redistributive effect of public and private social programmes: a cross-country empirical analysis. Int Soc Secur Rev 2010;63:1-19. 